\title{
O estatuto da melancolia e da mania em psicanálise: um percurso de Freud a Klein
}

\section{The statute of melancholy and mania in psychoanalysis: a path from Freud to Klein}

\author{
Evelyn Gomes Barbosa ${ }^{1}$, Érico Bruno Viana Campos ${ }^{2}$
}

\begin{abstract}
Resumo
Este artigo de revisão de literatura pretende abordar o estatuto da melancolia na psicopatologia psicanalítica clássica, buscando caracterizar o lugar da mania nesses quadros. Partimos da dificuldade de sistematização sobre os estados e estruturas ligados às síndromes depressivas e a relação entre melancolia e os estados maníacos. Traçamos um breve histórico sobre a classificação nosográfica da mania e da melancolia na psiquiatria para encaminhar um percurso teórico na psicanálise clássica que se inicia com Freud, passa por Abraham e chega a Klein. A caracterização efetuada da temática demonstra sua multiplicidade de sentidos, sua heterogeneidade conceitual e diversidade referencial. O principal eixo de problematização é a tensão entre a inserção da melancolia como um quadro psicótico e a depressividade como uma condição estruturante da personalidade, bem como a adesividade necessária dos delírios maníacos aos quadros melancólicos. Conclui-se que mesmo na tradição clássica das relações de objeto não há consenso sobre essas questões, necessitando de articulações e desenvolvimento para serem melhor integradas teoricamente.
\end{abstract}

Palavras-chave: Psicanálise; Psicopatologia; Melancolia; Depressão; Mania.

\begin{abstract}
This literature review article aims to address the status of melancholy in classical psychoanalytic psychopathology, seeking to characterize the place of mania in these settings. We start from the difficulty of systematizing the states and structures linked to depressive syndromes and the relationship between melancholy and manic states. We trace a brief history on the nosographic classification of mania and melancholy in psychiatry, following a theoretical path in classical psychoanalysis that begins with Freud, passes through Abraham and reaches Klein. The characterization of the theme demonstrates its multiplicity of meanings, its conceptual heterogeneity and referential diversity. The main axis of discussion is the tension between the insertion of melancholy as a psychotic condition and depression as a structuring condition of the personality, as well as the necessary adhesion of manic delusions to melancholic conditions. It is concluded that even in the classic tradition of object relations there is no consensus on these issues, requiring articulations and development to be better theoretically integrated.
\end{abstract}

Keywords: Psychoanalysis; Psychopathology; Melancholy; Depression; Mania.

\footnotetext{
${ }^{1}$ Psicóloga pela Universidade Estadual Paulista (Unesp), Bauru, São Paulo, Brasil. Formação em Psicoterapia Psicanalítica pelo Instituto de Estudos Psicanalíticos de Bauru, Bauru, São Paulo, Brasil. E-mail: evelyngobar@gmail.com

${ }^{2}$ Doutorado em Psicologia pelo Instituto de Psicologia da Universidade de São Paulo (IPUSP), São Paulo, São Paulo, Brasil. Professor na Universidade Estadual Paulista, Bauru, São Paulo, Brasil.E-mail: ebcampos@fc.unesp.br
} 


\section{Introdução}

Os estudos de Psicopatologia e Clínica Psicanalítica encontram dificuldade na sistematização teórica sobre os estados e estruturas ligados às síndromes depressivas. Isso ocorre em primeiro lugar pela própria derivação psicopatológica que se construiu a partir da noção cultural de melancolia, presente na tradição ocidental desde a Antiguidade (PERES, 2003). Em segundo lugar, pelas próprias indefinições iniciais de Freud (1917/2010) em circunscrever um lugar nosológico para o luto, a melancolia e a depressividade em sua teoria e em contraposição à tradição médica e psiquiátrica de seu tempo (TEIXEIRA, 2005). Decorre daí uma já vasta literatura que tematiza sobre considerar a melancolia uma estrutura própria ou uma subcategoria da estrutura psicótica (PERES, 1996) ou de organizações limítrofes (BERGERET et al., 2006), bem como sobre a diferenciação entre estrutura melancólica e sintomas depressivos em diferentes arranjos estruturais (McWILLIAMS, 2014), ou mesmo os critérios diagnósticos para tais classificações (RODRIGUES, 2000). Por fim, no contexto do peso dos quadros depressivos na casuística das psicopatologias contemporâneas e na discussão sobre suas configurações em termos estruturais, a questão da diferenciação entre depressão e melancolia tem sido resgatada (CAMPOS, 2016).

Contudo, pouco se discute a relação intrínseca estabelecida entre melancolia ou depressão e os estados maníacos, tomando como ponto pacífico o binômio "maníaco-depressivo", mesmo que deslocado para o âmbito de uma bipolaridade afetiva ou diluído no contexto mais geral da condição limítrofe ou borderline. Esse deslocamento parecenos ocultar justamente a especificidade do estado maníaco em sua relação estrutural e descritiva com sintomas psicóticos. A caracterização dos estados maníacos decorre da sua condição delirante, em relação com delírios de grandeza e persecutórios, próprios das configurações psicóticas clássicas. É também digno de nota que os estados maníacos raramente sejam considerados de forma autônoma ou em uma especificidade própria na psicopatologia psicanalítica (CAMPOS, 2016; VERTZMAN; COELHO JUNIOR, 2019). Diante desse contexto é que nos interessamos em trabalhar com o tema.

Tanto para a psiquiatria quanto para a psicanálise a noção de psicose maníaco-depressiva está relacionada à história geral da melancolia. $\mathrm{Na}$ psiquiatria clássica, a melancolia foi entendida a partir do viés da psicose, melhor dizendo, da psicose maníaco-depressiva. Essa localização se deu na psicopatologia psiquiátrica a partir da sistematização basilar de Emil Kraepelin de três grandes quadros psicóticos: a paranoia, a loucura maníaco-depressiva e a demência precoce - esta última posteriormente denominada por Eugen Bleuler de esquizofrenia (TENÓRIO, 2016).

Mas nem sempre foi assim. A mania e a melancolia eram consideradas afecções independentes uma da outra desde a Antiguidade, embora a relação entre elas fosse também reconhecida desde aquela época em razão de sua alternância e possível mútua implicação (BIRMAN, 2010). Ao final do século XIX, esse entendimento passou a sofrer modificações, quando Falret e Baillanger, separadamente descreveram a mania e a melancolia em uma mesma enfermidade. Na França, a partir de 1883, Ritti passou a afirmar a existência de uma doença, com crises sucessivas de mania e melancolia no mesmo indivíduo. Na Alemanha, esses casos foram estudados e denominados de psicose periódica (BIRMAN, 2010). A evolução desses estudos culminou então na descrição detalhada feita por Kraepelin, que se debruçou sobre as crises maníacas e melancólicas, bem como sobre os estados de transição entre elas. Sob o termo loucura maníaco-depressiva, ele abrangeu todas as psicoses antes descritas (intermitente, circular, periódica, de dupla forma e alterna) e excluiu a melancolia involutiva desses quadros, mantendo o status independente dessa enfermidade.

Na psicanálise, desde Freud, existe uma certa compreensão da distinção entre neurose e psicose, mas o lugar da melancolia nunca foi precisamente determinado. O próprio Freud ao se debruçar sobre a melancolia evita fazer uma classificação mais estrutural, para pensar a melancolia relacionada 
ao trabalho do luto. É importante lembrar que a psicanálise surgiu tratando dos pacientes neuróticos, sendo que, desde o início, a compreensão das psicoses e seu tratamento foi uma vertente de interesse e de algum trabalho clínico, que, porém, só foi ampliada e consolidada a partir dos psicanalistas pós-freudianos.

Do ponto de vista da clínica, é relevante diferenciar e contextualizar episódios delirantes, uma vez que eles podem estar presentes tanto em depressões profundas, quanto em quadros psicóticos, além de quadros de oscilação entre mania e depressão. O diagnóstico diferencial desses episódios para a psicanálise não se restringe a uma caracterização objetiva do quadro sintomatológico, necessitando de uma interpretação de caráter psicodinâmico e estrutural. Portanto é relevante para o clínico, principalmente no contexto das psicopatologias contemporâneas, que transitam entre neurose e psicose, munir-se de critérios que possam ajudar a esclarecer o diagnóstico, para além de um ponto de vista meramente descritivo.

A compreensão de como a psicopatologia psicanalítica entende os quadros psicóticos se faz importante para fazer uma caracterização diferencial entre os sintomas delirantes da mania e dos sintomas delirantes da psicose, compreendendo a inserção da psicose maníaco-depressiva na problemática da psicose. Entendemos que essa caracterização seja importante para a condução do tratamento, tendo, portanto, implicações técnicas em psicanálise. Propomos, então, fazer uma discussão de caráter teórico e não clínica. Trata-se nesse sentido de um ensaio teórico baseado em uma revisão de literatura narrativa e não-sistemática, orientada por autores primários clássicos e comentadores de nossa preferência.

\section{Contribuições de Sigmund Freud}

Desde o início das contribuições freudianas, nas correspondências a Fliess, é possível notar a dificuldade de englobar numa única entidade um quadro tão variado, o que se vê pela pluralidade de termos usados para referir-se à melancolia.
Nos rascunhos E e G, o autor arrola muitos sintomas para descrever o quadro melancólico, mas não se preocupa em diferenciar o uso das palavras melancolia e depressão. Porém, aponta para a existência de uma anestesia psíquica que estaria presente na melancolia, mas não na depressão. Para o melancólico, haveria uma insuficiência nas representações, um buraco na esfera psíquica, uma hemorragia interna, causadora de um empobrecimento da excitação, que por sua vez, leva os neurônios a abandonarem a excitação, gerando dor (PERES, 2003). Por outro lado, quando há excesso de comunicação neuronal, o quadro produzido seria a mania. Essa dinâmica aponta para um curso natural de alternância, em que um excesso de excitação (mania) leva a um empobrecimento (melancolia). Tal explicação se assemelhava às primeiras indicações de variações de intensidade em um circuito energético neuronal para explicar as oscilações de humor e que, em última instância, levarão às hipóteses sobre a transmissão neuronal e a expressão psíquica na produção da angústia (CAMPOS, 2004).

Uma questão que pode se colocar nesta apreciação inicial é que a melancolia denunciaria uma fragilidade e uma insuficiência que se apresentam como constitutivas e estruturais, onde se destaca uma experiência de carência energética e afetiva e não de excesso. Nesse sentido já se anuncia a noção de luto como paradigma normal da melancolia, tendo como ponto central a perda. A relação entre esses conceitos será melhor explicada no artigo de 1917. Nesse estudo, cujo tema central é a perda, Freud (1917/2010) busca compreender as respostas de um sujeito diante de uma perda, real ou imaginária, ou seja, da morte, abandono ou decepção vinda de uma pessoa amada, ou da perda de um ideal ou abstração que ocupa o lugar de um objeto amado (QUINODOZ, 2007).

Partindo dessas indagações, Freud (1917/ 2010) passa a diferenciar o luto da melancolia e acaba por trazer importantes contribuições para a teoria do $e u$, enfatizando uma divisão do sujeito, em que uma parte toma a outra como objeto, tratando-a com intensa crueldade, evidenciando o 
papel severo do ideal de $e u$ e o conflito entre essas duas partes do $\mathrm{eu}$, característico da melancolia. $\mathrm{O}$ autor também descreve sistematicamente os elementos envolvidos nessa dinâmica: a introjeção oral do objeto perdido, a identificação com esse objeto por regressão do amor ao narcisismo, o retorno contra o próprio sujeito do ódio dirigido ao objeto. Assim, a identificação narcísica tem papel fundamental no processo melancólico. Na melancolia, o sujeito fica incapaz de retirar sua libido do objeto perdido e liberá-la para ser dirigida a outro objeto, como ocorre no luto normal. Para não se separar do objeto, o ego o sequestra para dentro de si, ficando com ele confundido.

$\mathrm{O}$ autor afirma então que "a peculiaridade mais singular e mais carente de explicação, na melancolia, consiste na tendência a se transformar em mania, um estado com sintomas opostos aos dela" (FREUD, 1917/2010, p. 186), o que indica que para ele seria indispensável estender à mania a explicação sobre a melancolia, oferecendo uma orientação inicial, sustentada em dois pontos. Primeiramente, a impressão geral da psicanálise é de que a mania e a melancolia não têm conteúdo diferente, ou seja, "lutam com o mesmo 'complexo', ao qual o Eu provavelmente sucumbe na melancolia, enquanto na mania ele o sobrepuja ou põe de lado" (FREUD, 1917/2010, p. 187). Em segundo lugar, há determinantes econômicos comuns para os estados que fornecem o modelo normal da mania, ou seja, um grande investimento de energia psíquica, efetuado por muito tempo, tornou-se desnecessário. Assim, a energia fica livre para ser usada de outras formas, com outras possibilidades de descarga. Freud afirma que "a mania não é senão um triunfo desse tipo, com a diferença de que nela permanece oculto ao Eu aquilo que superou e sobre o que está triunfando" (FREUD, 1917/2010, p. 188). Ou seja, a situação ou objeto que exigia tamanho investimento libidinal não existe mais e agora o eu pode sobre ela triunfar. Porém, o eu desconhece aquilo sobre o que triunfa, assim como na melancolia, não sabe sobre aquilo que perdeu.

No caso do luto normal, também há absorção total das energias do eu e superação da perda do objeto, mas não se explica com facilidade o fato de que, uma vez transcorrido, não se produza a condição econômica para uma fase de triunfo. Tampouco se sabe exatamente por quais meios econômicos o luto normal leva a cabo sua tarefa. A hipótese de Freud é de que o rompimento de vínculo entre o eu e o objeto perdido se dê de forma tão lenta e gradual, que, ao final do trabalho de luto, o dispêndio requerido tenha sido paulatinamente dissipado.

Outra diferença importante entre o luto e a melancolia - e que terá consequência sobre o entendimento da mania - é que na melancolia a relação com o objeto é menos diferenciada, por conta de se estabelecer em termos narcísicos e sendo dificultada pelo conflito de ambivalência. Esta, por sua vez, pode ter origem na história do vínculo amoroso do $\mathrm{eu}$ ou nas vivências causadas pela ameaça de perda do objeto. Na melancolia, inconscientemente, amor e ódio lutam entre si em constantes batalhas em torno do objeto.

É interessante notar que na apreciação inicial da melancolia que Freud faz nesse texto, a ênfase recaia sobre a descrição do mecanismo de identificação narcísica na aproximação com o luto pelo objeto de amor. É apenas aventado que o mecanismo implique em uma regressão e se estabeleça a partir de uma fixação em um modo de relação de objeto de caráter narcísico. Também há só uma tênue indicação de sua relação com a introjeção oral e o objeto primário. Mas o principal é que o autor não se aventura a fazer uma categorização nosográfica do tema, ou seja, classificar como neurose ou psicose, embora indique que se trata de uma neurose narcísica, nome que na época designava todos os quadros que não as neuroses de transferência que eram a matriz clínica original do trabalho psicanalítico. Do mesmo modo, a questão da relação com a mania é abordada de forma ainda incipiente.

A relação entre $e u$ e ideal de $e u$ será melhor examinada em Psicologia das massas e análise do eu (FREUD, 1921/2011), em que o autor afirma haver uma tensão na organização psíquica normal em que o ideal do eu representa as exigências dos 
pais sobre o sujeito, enquanto na organização patológica essa tensão pode se acentuar, o que explicaria as alternâncias entre os estados melancólicos e maníacos. A hipótese de Freud é que a passagem da melancolia à mania deve-se à dissolução do ideal do $e u$ no $e u$, como resultado de uma rebelião periódica do eu contra seu ideal.

No texto Neurose e psicose, Freud (1924a/ 2011) integra as recém formuladas noções de $e u$, $i d$ e supereu à sua compreensão sobre a neurose e a psicose. Na neurose de transferência, o conflito entre o eu e o id advém da recusa de uma moção pulsional indesejável, da qual o eu se defende através da repressão. Porém, o conteúdo reprimido não é mantido para sempre no inconsciente e ressurge na forma de um sintoma substituto que o representa. O sintoma é, portanto, uma formação de compromisso. No caso da psicose, é a relação entre o eu e a percepção da realidade que é perturbada, de modo que não só a realidade externa não é mais percebida, como também o mundo interno, fruto de percepções guardadas na memória. Freud propõe que o eu cria para si um mundo novo, interno e externo, construído de acordo com os desejos do $i d$, uma vez que a realidade se opôs gravemente ao desejo e tornou-se insuportável. Nesse contexto, apresenta um remanejamento em sua categorização psicopatológica, as neuropsicoses narcísicas, cujo protótipo é a melancolia e que ele situa a meio caminho entre as neuroses de transferência e as psicoses. A forma que o eu encontra para evitar os conflitos com as instâncias que o dominam é deformar a si próprio e utilizar um mecanismo análogo à repressão para se separar do mundo exterior: uma retirada do investimento que ele havia situado fora.

Já em $A$ perda da realidade na neurose e na psicose, Freud (1924b/2011) põe em paralelo a neurose e a psicose, examinando suas diferenças e semelhanças a partir dos conflitos e relações do eu com o id e com o supereu, bem como abordando as perturbações na relação com a realidade nas duas afecções. Nesse texto, o autor relativiza o que havia afirmado sobre a diferença entre neurose e psicose, uma vez que no artigo anteriormente mencionado, a diferença era que na psicose o eu negava a realidade exterior e na neurose ele a aceitava, enquanto agora reconhece a perturbação da relação com a realidade nas duas afecções, porém de natureza diferente. Distingue assim dois momentos nos modos de entrada em cada um dos dois quadros. Na neurose, num primeiro momento, há a perda da realidade, seguida da formação do sintoma, ou seja, o fragmento da realidade evitado produz a repressão e esse fragmento é evitado, em forma de fuga. Na psicose, ocorre uma negação da realidade como característica da recusa a perceber a realidade exterior. A entrada na psicose dá-se também em dois momentos: no primeiro, o eu se separa da realidade através da negação; no segundo, cria-se uma nova realidade a fim de compensar a perda e reparar os desgastes. Tal é o mecanismo de formação dos delírios e das alucinações, como expressões de porções da realidade que foram negados e reconstruídos.

Ambos os textos são importantes para uma classificação nosográfica das neuroses de transferência, das neuroses narcísicas e das psicoses, para o entendimento das relações de conflito entre as instâncias psíquicas em cada afecção e para a descrição dos tipos de rompimento com a realidade em cada caso e as possíveis formas de reconstituição do vínculo entre ego e realidade interior e exterior. Porém, Freud não faz uma apreciação direta da fase maníaca relacionada à melancolia, tampouco diz algo a respeito de seus aspectos delirantes. Arriscamos dizer que um episódio maníaco pode ser classificado a partir de seu grau de dissociação da realidade, mas a questão não para aí, pois, além do episódio é preciso entender a dimensão estrutural, ou seja, avaliar o contexto da estrutura de personalidade em que os episódios se inserem. Do ponto de vista estrutural, podemos apenas inferir uma relação da mania com a melancolia e, através desse vínculo, incluir a primeira entre as neuroses narcísicas. Um ponto a ser destacado é a introdução das noções de negação da realidade, que aparece como mecanismo de defesa próprio da psicose.

Freud voltará a abordar as relações do eu com a realidade e com o supereu, colocando o humor como forma de triunfo do narcisismo, de 
afirmação da invulnerabilidade do $e u$, que se recusa a deixar-se afligir pela realidade, negando-a, e de imposição do princípio do prazer (FREUD, 1927/2011). Tais estados são característicos de processos regressivos ou reacionários e são meios que a psique humana desenvolveu para fugir ao sofrimento numa série que se inicia na neurose e culmina na loucura, podendo incluir a intoxicação, o ensimesmamento e o êxtase. Também são processos que ocorrem na mania e na melancolia e a alternância entre os dois estados se devem a um deslocamento de quantidades de investimento de uma instância psíquica para outra. $\mathrm{O}$ texto não apresenta novidades sobre os estados maníacos e melancólicos, mas parece sugerir que a sua natureza patológica é uma questão de grau, já que também estão presentes no funcionamento normal dos indivíduos.

\section{Contribuições de Karl Abraham}

Karl Abraham foi o primeiro psicanalista a tratar de pacientes afetados por distúrbios maníacodepressivos. De fato, é na extensão dos primeiros trabalhos de Abraham (1927/1970) que Freud elabora as hipóteses contidas em Luto e melancolia (QUINODOZ, 2007). Foi um dos poucos psicanalistas a debruçar-se sobre o assunto, fazendo-o em vários artigos, dentre os quais se destaca, por seu caráter propositivo e sintético, o texto sobre a história do desenvolvimento da libido (AMARAL, 2014). Sua principal contribuição para o assunto foi conceber a díade depressão/mania como uma psicose, ao contrário de Freud (1924a/2011) que hesitava quanto a essa classificação e ao final acabou diferenciando as psicoses da melancolia, deixando apenas esta última na categoria de neuroses narcísicas.

A posição de Abraham converge com a de Freud, no sentido de que a mania é uma experiência equivalente a uma intoxicação por droga que revoga a influência do supereu. Ele também supõe que na mania há um momento de suspensão do recalque análogo ao do chiste. Amaral (2014, p. 4950) rejeita essa posição, pois, para ela, Abraham "deixou-se iludir pela aparência de euforia e a confundiu com alegria" ignorando que na mania "há uma atividade frenética, impositiva e incessante" que não está presente no modelo do chiste.

No seu estudo do desenvolvimento da libido (ABRAHAM, 1927/1970), o autor aborda a relação da melancolia com as neuroses obsessivas, pois essas doenças apresentam processos de desprendimento da libido do mundo exterior que são similares entre si. Por outro lado, não havia esclarecimentos sobre as diferenças entre a melancolia e as neuroses obsessivas, tampouco sobre a causa específica das psicoses maníaco-depressivas e ele vai procurar essa causa em estágios pré-genitais do desenvolvimento da libido descritos por Freud. Para ele, as afecções se assemelham no fato de que é possível encontrar sintomas obsessivos na melancolia, assim como os neuróticos obsessivos costumam passar por períodos e estados de depressão. Abraham chama a atenção para a importância de dois processos: a regressão da libido à fase oral e o mecanismo de introjeção, de tal forma que "a introjeção do objeto de amor constitui uma incorporação do mesmo, acompanhando a regressão da libido ao nível canibalesco" (ABRAHAM, 1927/ 1970, p. 83). Cabe ressaltar que a introjeção e a incorporação associam-se ao que Freud chamou de identificação narcísica na melancolia.

Para Freud, um fato fundamental na melancolia é a perda do objeto, que precede o início da doença. Isso não ocorre no caso do paciente obsessivo. Apesar da ambivalência em relação ao objeto e do medo de perdê-lo, o neurótico o mantém. Abraham propõe que se diferenciam duas subfases do estágio anal, justamente para diferenciar os quadros melancólicos dos quadros obsessivos. A libido do obsessivo encontra-se fixada no nível posterior da fase sádico-anal, enquanto que a do melancólico encontra-se no nível inferior desta mesma fase. O abandono, pelo melancólico, das relações com o objeto leva a regressão da libido a pontos mais primitivos, ou seja, ao nível oral canibalesco. O autor também estabelece entre essas duas subfases o ponto de diferenciação clara entre ego e objeto e, portanto, o nascimento do que ele 
chama de amor objetal. Assim, a relação de objeto sádica do obsessivo é de fato objetal, enquanto a do melancólico é de caráter narcísico. Daí também a base para diferenciar a primeira como neurose e a segunda como psicose. Assim, o fato que conduz à doença melancólica é a perda do objeto de amor, seguido pela introjeção deste objeto perdido. Tal introjeção tem "o caráter de uma incorporação física, por via bucal" (ABRAHAM, 1927/1970, p. 97), ou seja, é um processo através do qual o melancólico traz o objeto perdido novamente à vida, alojando-o dentro de seu eu. Nesse sentido, a melancolia é uma forma arcaica de luto.

Contudo, se no luto há uma perda real (a morte do objeto amado) e consciente e a introjeção visa a preservar o objeto, na melancolia, o conhecimento consciente da perda tende a abandonar o sujeito e as relações com o objeto ficam de tal forma perturbadas e marcadas pela ambivalência, que o conflito só se resolve com o sujeito dirigindo a hostilidade para si mesmo. Consequentemente, todo sentimento amoroso é ameaçado por seu oposto, de modo que uma "frustração" por parte do objeto pode causar uma carga de ódio que retira os investimentos do objeto e esta retirada conduz ao seu completo abandono. A ambivalência da vida amorosa coloca o melancólico em conflitos particularmente graves, a ponto de atingir sua relação com o objeto amado e com demais objetos e interesses que o circundam. O melancólico, então, caracteriza-se não só pelo autodesprezo, mas por um sentimento de superioridade que pode ser representado pela quantidade de autoadmiração em relação aos efeitos de seus pensamentos. Trata-se, então, de uma atitude ambivalente da libido em relação ao eu e as alternâncias de estados depressivos e maníacos pode ser explicada por essa ambivalência.

No que diz respeito ao desencadeamento do mecanismo melancólico, parece-nos que tanto Freud quanto Abraham, ao se referirem a objetos de amor, estão tratando-os como objetos secundários. Logo adiante, ao analisar mais detalhadamente o processo de introjeção, Abraham vai descrever a fase oral da libido em dois estágios: um nível primário, em que a criança ainda não se diferencia do objeto e sua libido está ligada ao ato de sugar; um nível secundário, em que o ato de sugar é substituído pelo ato de morder. Neste nível tão primitivo, o objeto principal na vida da criança é a mãe, portanto, seu objeto original.

$\mathrm{O}$ autor ressalta que o desapontamento amoroso que culmina na perda do objeto não se trata apenas de "um caso sentimental infeliz" (ABRAHAM, 1927/1970, p. 117), mas de uma perda de objeto com efeito patogênico, que foi sentida no inconsciente como a "repetição de uma experiência traumática infantil original" (ABRAHAM, 1927/970, p. 117, grifos nossos), fortemente marcada pela compulsão à repetição, o que explica a grande frequência de recidivas que ocorrem nos casos de psicose maníaco-depressiva.

Vê-se, portanto, que Abraham avança na circunscrição da dinâmica própria dos quadros melancólicos, efetivando demarcações nosográficas importantes. O autor também propõe uma enumeração dos fatores etiológicos que, em conjunto, resultariam em uma depressão melancólica, a saber: 1) um fator constitucional, dado por uma exacerbação do erotismo oral, que facilita as condições para o fator seguinte; 2) uma fixação especial da libido no nível oral; 3) uma grave lesão ao narcisismo infantil, produzida por sucessivos desapontamentos amorosos durante a infância e relacionada a um desapontamento inicial vindo de seus pais; 4) a ocorrência do primeiro desapontamento amoroso antes da superação dos desejos edipianos; 5) a repetição do desapontamento primário na vida posterior, colocada como a causa do desencadeamento da melancolia (ABRAHAM, 1927/1970). Ou seja, os desapontamentos sucessivos são repetições do original, de forma que toda a ira do sujeito estará dirigida não a qualquer objeto, mas a esse objeto especial, o qual mais amara na infância e que foi posteriormente perdido. A depressão melancólica tem, portanto, um protótipo infantil.

Contudo, Abraham trata da melancolia sem dar atenção especial à fase maníaca, em parte pela escassez de material para observação que ele possuía até então e, em parte, acompanhando a 
tendência da psicanálise da época de compreender a melancolia independentemente do conhecimento dos processos envolvidos na mania. $\mathrm{O}$ autor não se aprofunda na descrição e debate do caráter delirante dos sintomas maníaco-depressivos, mas menciona as ideias delirantes que se relacionam com as autoacusações do melancólico. Ele atribui esse aspecto delirante ao "caráter puramente narcísico do curso do pensamento" (ABRAHAM, 1927/1970, p. 116). Tanto o auto-ódio como o autoamor (de que o melancólico também é capaz, como se vê nos pensamentos de superioridade e superestimação do ego) são efeitos de um narcisismo que ora atua como sendo positivo e ora negativo. Abraham então repisa a ideia freudiana da exaltação por emancipação da libido que estava retida, com a diferença que ele dá maior acento na dimensão oral introjetiva.

A introjeção de objetos tem papel importante para a diferenciação entre a melancolia e a paranoia e para a ocorrência ou não de delírios nessas enfermidades. Na paranoia, o sujeito representa o perseguidor por meio de uma parte de seu corpo e crê que o carrega dentro de si, querendo, mas não podendo dele se livrar. Quando o paranoico perde as relações libidinais com seu objeto, essa perda equivale à destruição do mundo, e ele busca compensá-la e reconstruir seu objeto perdido. Ocorre algo semelhante ao melancólico, que introjetou a totalidade do objeto através da incorporação oral. Porém, o paranoico incorporou seu objeto parcialmente, através de um processo anal. A libido do paranoico regride ao primeiro dos dois estágios sádico-anais e a sua atitude para com o objeto retorna ao estágio da introjeção parcial. A hipótese - que o autor afirma com ressalvas - para a ausência de delírios paranoicos na melancolia é que ela se deve aos "diferentes efeitos da introjeção, segundo seja ela total ou parcial em sua extensão e oral ou anal em seus meios" (ABRAHAM, 1927/ 1970, p. 148).

Se a melancolia é marcada por um narcisismo negativo, uma vez livre de seu supereu, é possível que o narcisismo entre numa fase positiva. A libido que estava dirigida ao $e u$, agora pode ser investida nos objetos externos, algo que o indivíduo faz com alto grau de voracidade, que se expressa num aumento de sintomas de caráter oral, por exemplo, aumento de apetite, não só por alimentos, mas também sexual, necessidade de apreender novas impressões e experiências, assimilando dentro de si todos os objetos possíveis.

Em síntese, Abraham fez uma detalhada análise sobre a fase melancólica da psicose maníacodepressiva, comparando-a com a neurose obsessiva, principalmente no que se refere às relações do sujeito com seu objeto em cada afecção. Com relação ao desenvolvimento da libido, situou as causas da melancolia em estágios primitivos de sua organização, chamando atenção para seu caráter cíclico, como efeito da compulsão à repetição. Quanto à mania, fez uma conceituação e uma descrição de sintomas próprios desta fase, porém, acaba não se debruçando sobre os aspectos delirantes de tais sintomas, apesar de indicar suas diferenças gerais em relação à paranoia. De qualquer forma, o autor endossa a visão de que a mania é parte da dinâmica melancólica e estabelece as bases na teoria do desenvolvimento psicossexual da libido para a caracterização das diferentes entidades nosográficas na psicopatologia psicanalítica. Também é responsável por estabelecer de forma mais clara um duplo eixo no desenvolvimento da personalidade em psicanálise: o desenvolvimento da libido e o desenvolvimento do amor objetal.

\section{Contribuições de Melanie Klein}

Dentre as principais pioneiras da escola das relações de objeto, encontra-se Melanie Klein. Além de sua vertente de trabalho com crianças, destaca-se também o seu interesse pela matriz clínica das psicoses. As perdas e a melancolia fizeram-se presentes na vida de Melanie Klein desde muito cedo e influenciaram decisivamente seu pensamento teórico, que teve Sándor Ferenczi e Karl Abraham como importantes referências (CINTRA; FIGUEIREDO, 2010).

As contribuições de Melanie Klein para a teoria e a técnica psicanalíticas podem ser divididas 
em três fases, sendo no contexto da segunda fase que ela escreveu os textos seminais Uma contribuição à psicogênese dos estados maníacodepressivos (1935/1996) e O luto e suas relações com os estados maníaco-depressivos (1940/1991). Se até então ela seguia Freud e Abraham, descrevendo suas descobertas em termos de estádios libidinais e da teoria estrutural do aparelho psíquico, a partir de 1934 passa a formular seus achados de acordo com o seu próprio conceito de posições. Tal mudança não se desalinha com o conceito de $e u$, supereu e $i d$, mas busca definir a estrutura real do eu e supereu e as características de seus relacionamentos nos termos das posições esquizoparanoide e depressiva (CINTRA; FIGUEIREDO, 2010).

Para Klein, ao nascer, o bebê já é capaz de experimentar ansiedade, lançar mão de mecanismos de defesa e relacionar-se com objetos de forma primitiva, em fantasia ou na realidade (SEGAL, 1975). Ao conjunto de ansiedades, defesas e relações de objeto, Klein deu o nome de posição. Ela prefere o termo posição ao termo fase, pois as ansiedades, defesas e relações objetais não se limitam a um determinado período e podem reaparecer durante os primeiros anos da infância ou em determinadas condições internas ou externas. Considerando o aspecto cronológico do desenvolvimento humano, a posição esquizoparanoide antecede a posição depressiva; contudo, no desenvolvimento da teoria, Klein sistematiza antes a posição depressiva, para depois ressignificar toda a discussão prévia sobre o sadismo no vínculo entre o ego e o objeto e a noção de um superego precoce, e configurar propriamente o conceito da primeira posição (KLEIN, 1946/1996).

No artigo de 1935, Klein apresenta duas teorias interligadas: uma teoria do desenvolvimento inicial e uma teoria da origem da doença maníacodepressiva. Nessa fase do desenvolvimento, diante de uma importante mudança nas relações de objeto do bebê, ou seja, na passagem de uma relação com objeto parcial para uma com o objeto total, com a possibilidade de se identificar com esse objeto, mas também de perdê-lo, surgem ansiedades depressivas em relação a esse objeto, às quais se somam ansiedades persecutórias, o medo de perder o objeto e o impulso de repará-lo. Em face dessa situação, o bebê passará a se defender mobilizando defesas maníacas para aniquilar os perseguidores, de forma que possa lidar com a culpa e o desespero. A esse grupo de relações de objeto, ansiedades e defesas, Melanie Klein deu o nome de posição depressiva. É "a fase de desenvolvimento na qual o bebê reconhece um objeto total e se relaciona com esse objeto" (SEGAL, 1975, p. 81).

O texto de 1940 expande e aprofunda o entendimento da posição depressiva e dos revezes que podem resultar de seu atravessamento, situando o luto entre os fenômenos da posição depressiva. Klein parte da relação estabelecida por Freud entre luto e melancolia para acrescentar que "[...] há uma íntima ligação entre o teste de realidade no luto normal e os processos arcaicos da mente." (KLEIN, 1940/1991, p. 387) e que "[...] a criança passa por estados mentais comparáveis ao luto do adulto, ou melhor, que o luto arcaico é revivido sempre que se sente algum pesar na vida ulterior." (KLEIN, 1940/1991, p. 387).

Klein expõe que são constituintes da posição depressiva a perseguição por parte dos objetos maus, juntamente com as defesas empregadas contra ela e o anseio pelo objeto amado. É justamente contra esse anseio que, no curso da posição depressiva, o ego desenvolverá um conjunto de defesas, que Klein já havia chamado de defesas maníacas ou posição maníaca, relacionando-se com a doença maníaco-depressiva. À negação e à onipotência somam-se também a idealização, como parte essencial da posição maníaca, juntamente com a ambivalência, para que através dessas defesas o eu possa se engrandecer contra seus perseguidores internos e contra a ameaçadora dependência em relação a seus objetos amados.

Entre os fenômenos da posição depressiva, destaca-se o papel do triunfo, que está relacionado ao desejo da criança de crescer, de igualar os feitos dos adultos, de triunfar sobre seus pais, de superar suas próprias dificuldades, de vencer seu próprio caráter destrutivo e de se tornar capaz de vencer e controlar seus objetos internos maus. Tudo isso 
pode funcionar como incentivo para o alcance de muitas realizações, porém, devido à culpa que gera, pode produzir justamente o contrário: prejudicar os esforços do sujeito e evitar as realizações.

$\mathrm{Na}$ passagem entre as posições, ocorre uma mudança na relação de objeto parcial para uma relação de objeto total. A diferença entre as duas modalidades de relações de objeto consiste no fato de que, nos primeiros meses de vida, o bebê se relaciona com um objeto de amor a ser consumido e devorado, um objeto que não possui autonomia nem integridade própria, nem é visto como um sujeito desejante. É mero prolongamento do corpo do bebê e entendido por ele como uma porção do mundo a ser consumida ou rejeitada de acordo com suas necessidades (CINTRA; FIGUEIREDO, 2010). Por ocasião do desmame, a criança começa a ter uma primeira ideia da mãe como objeto total, surgem os primeiros sinais de cuidado com o outro, levando-o em consideração, interessando-se pela sua preservação e temendo pelo seu desaparecimento. Ocorre, pois, uma mudança no ego, colocando-o numa outra posição, uma nova posição do ego em relação ao objeto. Nessa posição, estar diante do objeto é reconhecêlo como alguém que o bebê deseja preservar e que pode perder.

Juntamente com a mudança no ego ocorre uma mudança no tipo de ansiedade experimentada. Na relação de objeto parcial, a angústia sentida é do tipo paranoide (ou persecutória), em que a criança vive o medo de sofrer por parte do objeto, os mesmos ataques sádicos que havia sobre ele projetado. É uma angústia em que predomina a preocupação com a preservação do próprio ego, que vive um medo de aniquilamento. Todavia, quando a criança começa a ver o objeto como uma pessoa, a angústia experimentada passa a ser do tipo depressiva, que envolve o medo de ter danificado o objeto e o medo de que ele morra ou desapareça. É uma angústia mais complexa, pois além do medo, envolve a culpa pelos supostos danos ao objeto. Tal complexidade de sentimentos e ansiedades resulta na ambivalência, pois, se antes imperava o sadismo e o desejo de devorar e incorporar o outro, agora o sadismo encontra-se equilibrado por sentimentos amorosos e pelo desejo de preservação do objeto vivo.

Klein examina os estados depressivos em sua relação, de um lado, com a paranoia, e, de outro, com a mania. Retomando, resumidamente, a posição de Freud e Abraham, aponta como núcleo da melancolia a perda de um objeto amado e a instalação, via introjeção, desse objeto dentro do ego e se pergunta se o processo de introjeção seria específico à melancolia, já que a incorporação aconteceria tanto na paranoia quanto na melancolia, diferenciando-se quanto à relação do sujeito com o objeto e com alterações na constituição do ego que promoveu a introjeção. Essa nova relação com um objeto total traz ao sujeito a possibilidade de perda, pois "[...] só quando o objeto é amado como um todo é que sua perda pode ser sentida como um todo" (KLEIN, 1940/1991, p. 306). Ao mesmo tempo, a fantasia de que o objeto pode ser preservado no interior do indivíduo estimula o aumento da introjeção. Klein estabelece, para além de Freud e na esteira de Abraham, a divisão clara entre condição narcísica e condição objetal, nos termos dela: relação de objeto parcial e relação de objeto total. A perda da melancolia é no nível do objeto total e na paranoia do objeto parcial.

Temos então as situações fundamentais para a perda do objeto amado na posição depressiva: a identificação total do ego com os objetos bons internalizados, juntamente com a percepção de sua própria incapacidade de proteger esse objeto dos ataques do id e dos objetos persecutórios que foram internalizados. O ego vai se defender dessa situação através da introjeção do objeto bom e do mecanismo de fazer reparações ao objeto. Através desse mecanismo, o ego é impelido (uma vez que está identificado com o objeto bom) a fazer restituições, a reparar o objeto pelos ataques que lançara contra este. Nesta fase, diante da ausência da mãe, a criança crê que a devorou e destruiu e é atormentada por uma ansiedade relacionada a si mesma e à mãe boa que internalizou.

A culpa pelos ataques imaginários ao objeto e o desejo de devolver-lhe a integridade levam a 
criança a valer-se do mecanismo de reparação como forma de restaurar o objeto primário perdido. Porém, as ações de reparação nem sempre se dão de forma satisfatória e as defesas maníacas tornam-se mais fortes e frequentes. Na posição depressiva, as defesas maníacas incluem mecanismos que já estavam presentes na posição esquizoparanoide: divisão, idealização, identificação projetiva, negação etc., com a diferença de que na posição depressiva tais defesas são altamente organizadas, com uma maior integração do ego e dirigidas contra a ansiedade depressiva e a culpa (SEGAL, 1975).

As defesas maníacas têm seu papel no funcionamento equilibrado do aparelho psíquico, pois são reguladoras da intensidade das emoções, mas para isso, devem ter sua força superada pelas operações reais de reparação. Porém, nem todas as pessoas conseguem atingir esse funcionamento equilibrado e passam a vida alternando entre estados depressivos, carregados de culpa e medo, e estados maníacos, marcados pelo rompimento com a realidade e uso da negação do sofrimento e da morte. Tal é o quadro da psicose maníacodepressiva, "sendo esta um dos resultados patológicos mais graves da má travessia da experiência organizada em termos da posição depressiva" (CINTRA; FIGUEIREDO, 2010, p. 82).

A questão que se coloca é se os estados maníaco-depressivos são somente estados ou se refletem condições estruturais. Pensamos que as duas situações podem ocorrer. O aparecimento das defesas maníacas não é por si só um fenômeno patológico (SEGAL, 1975), pois elas desempenham um papel importante no desenvolvimento, como forma de resolução da depressão e superação do sofrimento. Com a diminuição das ameaças e do sofrimento, as defesas maníacas cedem lugar à reparação. Porém, quando essas defesas são excessivamente fortes, criam-se círculos viciosos e pontos de fixação que influenciam no desenvolvimento futuro e podem levar à predominância de formas de funcionamento características de uma estrutura.

Para Freud, a mania é uma forma de fugir do estado de melancolia e as duas carregam os mesmos conteúdos, mas Klein acrescenta que, na mania, o ego busca fugir não só da melancolia, mas também de uma paranoia que ele não consegue dominar, ou seja, a mania é também uma defesa contra a angústia paranoica (ETCHEGOYEN, 2017). Essa é uma distinção em relação a Freud e a Abraham, sendo uma novidade que vai dar a tônica da abordagem kleiniana.

Em suma, Melanie Klein situa a mania como uma defesa típica de estágios iniciais de desenvolvimento, que atua contra angústias psicóticas que permaneceram ou ressurgiram no curso da posição depressiva. Afirma que as defesas maníacas estão a meio termo entre a posição depressiva e posição esquizoparanoide e, portanto, são mais arcaicas que do que as defesas próprias da posição depressiva. A implicação desse entendimento para uma compreensão psicopatológica é que isso coloca a psicose maníaco-depressiva como uma enfermidade mais regredida do que a melancolia. Por outro lado, é digno de nota que Klein inverte o caminho das fixações libidinais que havia sido proposto por Abraham, já que para aquele autor a psicose maníaco-depressiva seria mais regredida do que a paranoia.

\section{Visão de conjunto}

Após a apresentação da fundamentação teórica clássica, recorremos a Vertzman e Coelho Junior (2019) para tecer comentários e sintetizar alguns pontos referentes ao objetivo específico almejado. Os autores procuram traçar um amplo panorama sobre as diversidades conceitual e referencial sobre os estados maníacos, problematizando a proposta freudiana de que a mania seria o triunfo sobre o mesmo complexo da melancolia e sugerem que a mania não pode ser totalmente recoberta pela lógica melancólica. Para eles, há alguns pontos sobre a mania que precisam ser considerados e articulados: 1) a relação de oposição entre mania e melancolia diante de um mesmo complexo; 2) a mania como triunfo diante do complexo vinculado ao objeto perdido; 3 ) o papel da mania no trabalho de luto; 4) o papel das defesas maníacas no processo de separação do objeto; 5) a heterogeneidade ou 
homogeneidade dos estados maníacos; 6) o papel das defesas maníacas na saúde.

Como dito no início deste artigo, a mania é pouco estudada pelos psicanalistas. Porém, os comentadores consideram que essa escassez não é um problema, pois acreditam que a compreensão da melancolia contém elementos suficientes para o entendimento da mania. Para o movimento psicanalítico as duas condições teriam raízes comuns, ou seja, a relação peculiar que o sujeito estabelece com o objeto e sua reação à perda. Assim, fica sugerido que a mania é apenas uma pequena parte da visão sobre a melancolia: "a mania seria um pequeno bairro afastado, dentro da grande metrópole melancólica. Uma espécie de avesso no qual a estrutura comum da metrópole se manifestaria de modo invertido apenas para confirmar sua lógica metropolitana e cosmopolita" (VERTZMAN; COELHO JUNIOR, 2019, p. 91). Seria necessário inverter a lógica perceptiva para compreender o que se passa no "bairro" e mirar a "metrópole" com um olhar provinciano, ou seja, examinar melhor o que se passa com a mania e abordar a melancolia com o mesmo olhar.

Como visto no início, Freud não teve como objetivo principal compreender as relações entre melancolia e mania. Ele buscava comparar a melancolia com o processo de luto e a apreciação da mania serviu para "discutir a relação ambivalente e dependente do melancólico com seus objetos primários" (VERTZMAN; COELHO JUNIOR, 2019, p. 91). Ante os impasses do enlutamento, a mania configura-se como um outro destino, selando a ferida narcísica que obriga o objeto a colonizar o eu, pela submissão ou pelo triunfo. Por não fazerem parte do objetivo principal, Freud deixa de lado algumas questões: o que a mania acrescenta ao quadro da melancolia e o que pode esclarecer sobre as saídas para o impasse melancólico? Existe alteração do quadro depressivo após a passagem por um quadro maníaco? O estado maníaco tem algum impacto mnêmico, mesmo que não seja em forma de recordação ou inscrição? Os impasses decorrentes da problemática do luto e da perda do objeto são semelhantes na melancolia e na mania? Apesar da importância dessas questões, os autores afirmam não estar em posição de respondê-las.

Os entendimentos decorrentes e os apontamentos de Abraham dizem respeito à economia do luto e seus desvios na melancolia. Nesse sentido, a mania distingue-se da melancolia na sua forma de contornar a impossibilidade da perda do objeto. O elemento usado para investigar os sintomas maníacos é a energia liberada pelo passageiro triunfo sobre o complexo. O conflito entre o eu e a consciência moral, que representa um modelo explicativo para a melancolia, ainda não se mostra um modelo explicativo suficiente para o entendimento da mania. A hipótese de Freud era que esse estado ocorre por uma quase fusão entre ego e ideal de ego, de forma que o modelo melancólico seria fundamento para uma concepção sobre a mania. Não são examinadas outras possibilidades de experiências maníacas e seus aspectos não patológicos nas relações precoces com o objeto também são deixados de lado. Esse último aspecto será encaminhado por Abraham e retrabalhado por Melanie Klein.

O sujeito maníaco vive num ritmo que apaga sua relação com o mundo e consigo mesmo, num tempo que é simultaneamente antes e depois, em que ocorre uma esterilização dos afetos e uma negação da afetividade. A labilidade afetiva demonstra que os afetos não duram o suficiente para produzirem transformação subjetiva. $\mathrm{O}$ vínculo com objeto ambivalente, narcisicamente identificado com o sujeito, se afrouxa. Paradoxalmente, o sujeito parece desvinculado do objeto, ao mesmo tempo em que o objeto atrai todos os seus esforços. O sujeito maníaco se refugia num tipo de ligação menos intencional com o mundo, pois a intencionalidade emocional o leva a uma perda que ele é incapaz de elaborar.

Um dos aspectos do quadro acima é o triunfo, descrito por Freud como uma reação diante do complexo relacionado à perda do objeto, porém, não é o único aspecto da aparente liberdade vivida pelo maníaco. A mania torna-se um enigma na melancolia, em razão do modelo econômico que faz 
do processo de luto uma reação natural à perda, tanto na saúde como na neurose. Freud afirmou que na melancolia acontece um trabalho semelhante ao luto, ainda que seja diferente e precocemente inacabado. Tal trabalho afasta o sujeito do jugo da sombra do objeto temporariamente, até que o complexo retorne, já que a melancolia é uma condição cíclica. Porém, Freud não responde por que se convoca um estado difuso e bizarro como a mania, uma vez que existem outras ferramentas psíquicas para se lidar com a ferida narcísica deixada pelo objeto perdido.

Para buscar responder o que a mania acrescenta ao processo melancólico, Vertzman e Coelho Junior (2019) valem-se das contribuições de Paul Laurent Assoun. Para esse autor, a mania é o ponto culminante da melancolia, um ponto de chegada da relação de objeto melancólica, que coloca em dúvida o suposto triunfo. Assim, a mania seria o resultado mais excepcional do processo melancólico. O que ela acrescenta ao processo são novas possibilidades de destino para os impasses do luto. $\mathrm{Na}$ mania, a reação à perda resulta em três aspectos que representam níveis crescentes de intensidade em relação ao desligamento do objeto. $\mathrm{O}$ que se nega é: 1) a perda do objeto; 2) o luto pela perda do objeto; 3) ou talvez o próprio objeto. O gozo maníaco resultaria do triunfo sobre a perda, o luto e o próprio objeto. Esse último aspecto sugere a condição de um processo psicótico, um tipo de loucura que se alimenta de se desvincular do objeto. Essa seria a condição de desencadeamento do delírio maníaco, colocando a mania, nesse caso, como um quadro definidamente psicótico.

Porém, as outras formas de negação não configuram sempre essa defesa tão radical e podem estar presentes em outras configurações como formas de reação ao luto. Portanto, os estados maníacos podem conter formas diversas de reação à perda que não somente a negação do objeto e o triunfo sobre ele, o que leva a outra suposição: estados maníacos podem ocorrer como resposta a outras formas de perda, ou seja, formas depressivas que se distinguem de processos tipicamente melancólicos (PINHEIRO; QUINTELA; VERTZMAN, 2009).
Já em nosso próprio encaminhamento teórico no percurso da tradição das relações de objeto, pudemos demonstrar que Klein apresenta uma proposta bem distinta a respeito da experiência maníaca. Para ela, o sujeito utiliza as defesas maníacas quando conseguiu conquistar os recursos psíquicos da posição depressiva, com a integração e introjeção dos aspectos bons e maus do objeto e sua ambivalência, porém não é capaz de enfrentar as demandas suscitadas pelas ansiedades depressivas. Para não regredir à posição esquizoparanoide, o indivíduo utiliza um recurso que o faz avançar, ao mesmo tempo negando e satisfazendo o problemático encontro com os objetos complexos. $\mathrm{O}$ aspecto mais evidente dessa operação é a ameaça à integridade do objeto bom, de modo que sua importância é diminuída, o que causa um processo de destruição do mundo interno baseada nessa negação.

Por outro lado, a defesa maníaca visa negar a ameaça de destruição do objeto e propiciar sua reparação. A destruição do mundo interno é fruto da onipotência, que além de destruir, torna possível a restauração permanente dos objetos destruídos, mantendo-os idealmente protegidos, de forma que o sujeito é capaz de controlá-los. Porém, o excesso na utilização dessa defesa produz esvaziamento psíquico, prevalência de destruição e incapacidade de realizar reparações genuínas. "A necessidade de controle absoluto da cena primária, característica dessa defesa, é geradora de uma descontinuidade subjetiva, transformando o maníaco numa figura de exceção expressa, em casos extremos, pelos seus delírios de grandeza" (VERTZMAN; COELHO JUNIOR, 2019, p. 95). Tal condição explicaria o caráter de loucura de alguns quadros maníacos e sua aproximação com a psicose.

Diante do exposto, pode-se sintetizar que três pontos são importantes para a discussão sobre a defesa maníaca: o papel da defesa maníaca na saúde, seu papel no processo de luto e a relação entre defesa maníaca e melancolia. A presença da defesa maníaca em processos de saúde relaciona-se à sua atividade reparadora, atuando com outras defesas para tornar suportáveis as ansiedades depressivas relacionadas à preservação dos bons objetos. 
Finalmente, é importante verificar se a defesa maníaca transforma ou complexifica a ideia freudiana de que a mania é o avesso da melancolia. O termo posição depressiva não deve ser confundido com a melancolia, pois essa posição é fundamental para que o sujeito possa vivenciar a ambivalência no contato com os objetos complexos e não pode ser considerada como uma saída melancólica. Para Klein, os objetos bons na melancolia tornamse objetos idealmente perfeitos que agridem o $\mathrm{eu}$, que, por sua vez, fica incapaz de suprir suas demandas vorazes. O que une essas duas defesas é a participação do objeto perfeito no desenrolar da melancolia. Não é possível definir se isso caracteriza uma oposição entre mania e melancolia na obra de Klein, mas, de qualquer forma, podese afirmar que a concepção de defesa maníaca indica a possibilidade de esta integrar processos reparadores na saúde e de fazer parte do processo de luto normal, não podendo ser reduzida, portanto, à lógica melancólica.

\section{Considerações finais}

A partir dessa discussão sobre a melancolia e os estados maníacos, é possível deduzir sua multiplicidade de sentidos, sua heterogeneidade conceitual e diversidade referencial. Em comparação com outras áreas, o campo nocional e psicopatológico é ainda incipiente. Ficamos com a impressão de dois modelos teóricos que não dialogam muito bem entre si. De um lado, a mania é vista como um processo de defesa contra os impasses e fragilidades narcísicas da ordem da melancolia, própria dos estados maníaco-depressivos, relacionada com o complexo melancólico, sendo um tipo de revolta contra o objeto que coloniza o eu, de acordo com Freud. De outro lado, na versão kleiniana e de autores da escola das relações de objeto, a mania é tida como uma defesa contra as ameaças da posição depressiva, baseada na onipotência de um interior artificial, que toma o lugar do eu e resulta em um desprezo pelo mundo dos objetos. Esses universos representam as duas visadas que necessitam de novas articulações para que possam ser mais bem colocadas em contato.

Do ponto de vista estrutural, as posições a respeito de onde situar a mania não são consensuais. Entendemos que a classificação da mania depende da tradição teórica que orienta a classificação e de sua vinculação ou não à lógica melancólica. Assim, se articulada à melancolia e vinculada aos quadros maníaco-depressivos, a classificação dos estados maníacos pode inserir-se em linhas teóricas distintas.

Em Freud, a relação da mania com a melancolia é abordada de forma ainda incipiente, sem que se faça uma classificação nosográfica precisa. $\mathrm{O}$ autor hesita quanto a classificar a melancolia como uma psicose propriamente dita e estabelece a categoria de neuroses narcísicas, termo que designava todos os quadros que não as neuroses de transferência. Nessa categoria ele incluiu a melancolia. Se os estados maníacos acompanham a lógica melancólica, podem, então, figurar também entre as neuroses narcísicas.

Karl Abraham concebeu a díade mania/ melancolia como uma psicose, sendo que sua nosologia acompanha a descrição da neurose obsessiva até chegarem a um ponto de distinção em que a psicose maníaco-depressiva acompanha o modelo da paranoia. O autor analisa a fase melancólica da psicose maníaco-depressiva, principalmente no que diz respeito às relações entre sujeito e objeto, e situa as causas da melancolia em estágios primitivos da organização da libido. Em relação à mania, fez uma conceituação e uma descrição de sintomas próprios desta fase, reforçando a visão de que a mania é parte da dinâmica melancólica.

Para Melanie Klein, a mania é uma defesa própria de estágios iniciais do desenvolvimento humano que tem o objetivo de atuar contra angústias psicóticas que permaneceram ativas ou ressurgiram no curso da posição depressiva. Tal defesa está a meio termo entre as posições depressiva e esquizoparanoide, sendo, portanto, mais arcaica que as defesas específicas da posição depressiva. Disso decorre que a psicose maníaco-depressiva 
é uma enfermidade mais regredida do que a melancolia, não podendo ser entendida a partir da lógica melancólica.

Diante do exposto, pode-se concluir que no percurso de Freud a Klein na vertente das relações de objeto podemos encontrar encaminhamentos distintos ao lugar e compreensão da mania, mas é possível afirmar que no encaminhamento mais axial da tradição das relações de objeto se efetua um descolamento e relativização do binômio melancolia e mania e o descolamento da melancolia do campo das psicoses. A respeito dos componentes delirantes dos estados maníacos, esperávamos encontrar na literatura elementos que nos auxiliassem a explicá-los e a encontrar semelhanças e diferenças entre o delírio maníaco e o delírio psicótico. Porém, os textos clássicos que abordamos não permitiram esclarecer essa questão, sendo necessário ainda avançar na literatura contemporânea dessa tradição e da psicopatologia psicanalítica, o que esperamos fazer em outra ocasião.

\section{Referências}

ABRAHAM, K. Teoria Psicanalítica da libido: sobre o caráter e o desenvolvimento da libido. Rio de Janeiro: Imago, 1970. Originalmente publicado em 1927.

AMARAL, N. A loucura lúcida: o estatuto estrutural da mania e da melancolia na clínica psicanalítica. 2014. Tese (Doutorado em Pesquisa e Clínica Psicanalítica) - Universidade do Estado do Rio de Janeiro, Rio de Janeiro, 2014.

BERGERET, J.; BECACHE, A.; BOULANGER, J. J.; CHARTIER, J. P.; DUBOR, P.; HOUSER, M. (org.). Psicopatologia: teoria e clínica. 9. ed. Porto Alegre: Artmed, 2006.

BIRMAN, Joel. A cena constituinte da psicose maníaco-depressiva no Brasil. História, Ciências, Saúde - Manguinhos, Rio de Janeiro, v. 17, n. 2, p. 345-371, 2010. Disponível em: https://bit. ly/3zaIdvR. Acesso em: 25 ago. 2020. Doi: http:// dx.doi.org/10.1590/S0104-59702010000600005

CAMPOS, É. B. V. A primeira concepção freudiana de angústia: uma revisão crítica. Ágora: Estudos em Teoria Psicanalítica, Rio de Janeiro, v. 7, n. 1, p. 109-128, 2004. Disponível em: https://bit. ly/3w5XMCW. Acesso em: 20 ago. 2020. http:// dx.doi.org/10.1590/S1516-14982004000100006

CAMPOS, É. B. V. Uma perspectiva psicanalítica sobre as depressões na atualidade. Estudos Interdisciplinares em Psicologia, Londrina, v. 7, n. 2, p. 22-44, 2016. Disponível em: https://bit. ly/3gINRT. Acesso em: 25 ago. 2020.

CINTRA, E. M. U.; FIGUEIREDO, L. C. Melanie Klein: estilo e pensamento. São Paulo: Escuta, 2010.

ETCHEGOYEN, H. Fundamentos da técnica psicanalítica. 2. ed. São Paulo: Artmed, 2017.

FREUD, S. Luto e melancolia. In: FREUD, S. Introdução ao narcisismo: ensaios de metapsicologia e outros textos (1914-1916). São Paulo: Companhia das letras, 2010. p. 170-194. (Obras completas; v. 12). Originalmente publicado em 1917.

FREUD, S. Psicologia das massas e análise do eu. In: FREUD, S. Psicologia das massas e análise do eu e outros textos (1920-1923). São Paulo: Companhia das letras, 2011. p. 9-100. (Obras completas; v. 15). Originalmente publicado em 1921.

FREUD, S. Neurose e psicose. In: FREUD, S. $O$ eu e o id, "autobiografia" e outros textos (19231925). São Paulo: Companhia das letras, 2011. p. 176-183. (Obras completas; v. 16). Originalmente publicado em 1924a.

FREUD, S. A perda da realidade na neurose e na psicose. In: FREUD, S. O eu e o id, "autobiografia" e outros textos (1923-1925). São Paulo: Companhia das letras, 2011. p. 176-183. (Obras completas; v. 16). Originalmente publicado em $1924 \mathrm{~b}$.

FREUD, S. O humor. In: FREUD, S. O futuro de uma ilusão e outros textos (1926-1929). São Paulo: Companhia das letras, 2011. p. 262-269. (Obras completas; v. 17). Originalmente publicado em 1927.

KLEIN, M. Uma contribuição à psicogênese dos estados maníaco-depressivos (1935). In: KLEIN, M. Amor, culpa e reparação e outros trabalhos (1921-1945). Rio de Janeiro: Imago, 1996. p. 301329. Originalmente publicado em 1935. 
KLEIN, M. O luto e sua relação com os estados maníaco-depressivos (1940). In: KLEIN, M. Amor, culpa e reparação e outros trabalhos (19211945). Rio de Janeiro: Imago, 1991. p. 385-412. Originalmente publicado em 1940.

KLEIN, M. Notas sobre alguns mecanismos esquizóides (1946). In: KLEIN, M. Inveja e gratidão e outros trabalhos (1946-1963). Rio de Janeiro: Imago, 1996. p. 44-63. Originalmente publicado em 1946.

McWILLIAMS, N. Diagnóstico psicanalítico: entendendo a estrutura da personalidade no processo clínico. 2. ed. Porto Alegre: Artmed, 2014.

PERES, U. T. Melancolia. São Paulo: Escuta, 1996.

PERES, U. T. Depressão e melancolia. Rio de Janeiro: Jorge Zahar, 2003.

PINHEIRO, T.; QUINTELLA, R.; VERZTMAN, J. Distinção teórico-clínica entre depressão, luto e melancolia. Revista Psicologia Clínica, Rio de Janeiro, v. 22, n. 2, p. 147-168, jul. 2010. Disponível em: https://bit.ly/2TdLQkk. Acesso em: 25 ago. 2020. Doi: http://dx.doi.org/10.1590/ S0103-56652010000200010

QUINODOZ, J.-M. Ler Freud: guia da obra de S. Freud. Porto Alegre: Artmed, 2007.

RODRIGUES, J. S. F. O Diagnóstico de depressão. Psicologia USP, São Paulo, v. 11, n. 1, p. 155-187. Disponível em: https://bit.ly/3ggx4Ru. Acesso em: 25 ago. 2020. Doi: http://dx.doi.org/10.1590/ S0103-65642000000100010

SEGAL, H. Introdução à obra de Melanie Klein. Rio de Janeiro: Imago, 1975.

TENÓRIO, F. Psicose e esquizofrenia: efeitos das mudanças nas classificações psiquiátricas sobre a abordagem clínica e teórica das doenças mentais. História, Ciência, Saúde - Manguinhos, Rio de Janeiro, v. 23, n. 4, p. 941-963, 2016. Disponível em: https://bit.ly/3cJGAMf. Acesso em: 25 ago. 2020. Doi: http://dx.doi.org/10.1590/s010459702016005000018

TEIXEIRA, M. A. R. Melancolia e depressão: um resgate histórico e conceitual na psicanálise e na psiquiatria. Revista de Psicologia da UNESP, Assis, v. 4, n. 1, p. 41-54, 2005. Disponível em: https://bit.ly/3ggOYUm. Acesso em: 25 ago. 2020.
VERTZMAN, J.; COELHO JUNIOR, N. E. Mania: um bairro pouco visitado. Ágora: Estudos em Teoria Psicanalítica, Rio de Janeiro, v. 22, n. 1, p. 87-98, 2019. Disponível em: https://bit. ly/3go81w6. Acesso em: 25 ago. 2020. Doi: https:// doi.org/10.1590/s1516-14982019001009 